\title{
MINI-INVASIVE SURGERY IN THE FIRST THREE YEARS OF LIFE
}

\section{Sica, F. Molinaro, M. Messina, M. Aglianò, R. Angotti, E. Bindi, F. Mariscoli}

\author{
Division of Pediatric Surgery, Department of Medical Science, Surgery and Neuroscience. \\ University of Siena, Italy
}

\begin{abstract}
Background: In the last 30 years mini-invasive surgery (MIS) has been widely used becoming an important and irreplaceable method, safe and highly reliable, in both the diagnostic and therapeutic treatment, for a variety of conditions in both the child and the newborn. This has led to a significant increase of the use of this approach in the pediatric population under the age of 3 years, with results similar to the open techniques. Materials and Methods: At the Department of Surgery, Medicine and Neuroscience at the University of Siena we conducted a retrospective study of patients aged less than three years of life underwent minimally invasive procedures. The clinical information was extrapolated from a prospective database. They included all patients treated from June 2003 to October 2014. Were considered for each patient demographics, associated diseases, surgical procedure, MIS approach, the instruments used, the duration of surgery and hospitalization, intraoperative and postoperative complications (early and late). Results: From a total of 933 minimally invasive procedures, $150(16 \%)$ were performed under the age of 3 years. The $76 \%$ of patients were males, $24 \%$ were females. Twenty-two patients (15\%) presented associated diseases. $53(35 \%)$ were diagnostic procedures, 97 (65\%) were therapeutic procedures. We treated: 13 esophageal atresia, 1 diaphragmatic hernia, 1 congenital cystic adenomatoid malformation (CCAM), 8 stenosis of the ureteropelvic junction , 2 disorders of sexual differentiation (DSD), 20 inguinal hernias, 75 cases of non-palpable testis, 15 cases of Hirschsprung disease, 10 cases of fundoplication, 4 cases of ovarian tumors, 6 cases of nephrectomy, 4 cases of eminefrectomy and 1 case of thymoma. In total we performed 6 (4\%) thoracoscopic procedures, $18(12 \%)$ in retroperitoneoscopy and $126(84 \%)$ in laparoscopy. 55 procedures (37\%) were performed in "one-trocar" technique. Among the remaining 95 (67\%), in 62 (41\%) we used a "3 mm" instruments, in 18 (12\%) "5 mm" instruments and in $15(14 \%)$ they were mixed $(3 / 5 \mathrm{~mm})$. The duration of the procedure was an average of 59 minutes (range: $20-135$ minutes) in diagnostic procedures and 184 minutes (range: 40-370 minutes) in the therapeutic procedures. We converted to an open technique in 14/150 (9\%). We reported no postoperative complication and incidentaloma no intraoperative complications. The following is $100 \%$ survival. Conclusions: MIS is probably the most important change that has taken place in the field of Pediatric Surgery in the last 30 years. The optimum benefits are to be found in the lesser surgical stress, the lower cavity contamination, the magnification of details, the reduced hospital stay, reduced morbidity or the best aesthetic result.
\end{abstract}

Key words: Mini-invasive surgery; thoracoscopy; retroperitoneoscopy.

\section{INTRODUCTION}

Since the end of ' 80 s mini-invasive surgery (MIS) has been widely used becoming an important and irreplaceable method, safe and highly reliable, in both the diagnostic and therapeutic treatment, for a variety of conditions in both the child and the newborn [1-6].

The purpose of our work was to evaluate the feasibility of the MIS comparing children younger than three years with the population over the age of 3 years.

\section{MATERIALS AND METHODS}

At the Department of Surgery, Medicine and Neuroscience at the University of Siena we conducted a ret- rospective study of patients aged less than three years of life underwent minimally invasive procedures.

The clinical information was extrapolated from a prospective database. They included all patients treated from June 2003 to October 2014.

For each patients we considered demographics, associated pathologies, the surgical procedure, the minimally invasive approach, the instruments used, the duration of surgery and hospital stay, the intraoperative and postoperative complications (early and late).

In connection with the feasibility of MIS in children under 3 years of life we compared statistically aspects of the population selected for the study and the rest of the patients older than 3 years who have undergone at MIS our center.

The parameters taken into consideration were the

Correspondence to:

Marina Sica

Division of Pediatric Surgery, Department of Medical Sciences, Surgery and Neuroscience, University of Siena

Polyclinic "Le Scotte", viale Bracci 16, 53100 Siena, Italy

Tel.: +39.577.586502; Fax: +39.577.586174

E-mail: sicamarina121@gmail.com 
conversion rate and the rate of early and late complications. The test used was the test of Fisher. We considered as significant a P value less than 0.05 .

\section{RESULTS}

A total of 933 minimally invasive procedures were performed, of these $150(16 \%)$ in children under three years. $114(76 \%)$ were male and $36(24 \%)$ females. 22 of 150 patients $(15 \%)$ had associated diseases, such as: esophageal atresia in 3cases, 1 case of diaphragmatic hernia, 1 case of congenital cystic adenomatoid malformation (CCAM), 8 cases of stenosis of the ureteropelvic junction, 2 cases of disorders of sex development (DSD), 20 cases of inguinal hernia, 75 cases of non-palpable testis, 15 cases of Hirschsprung disease, 10 cases of fundoplication, 4 cases of ovarian tumors, 6 cases of nephrectomy, 4 cases of eminefrectomy and 1 case of thymoma. In Figure 1 we show an intraoperative picture of congenintal diaphragmatic hernia.

Tables 1-3 includes all the procedures performed by laparoscopy, thoracoscopy and retroperitoneoscopy.

Of the 150 MIS procedures under 3 years, 53 (35\%) were diagnostic, 97 (65\%) therapeutic.

In total we performed $6(4 \%)$ thoracoscopic procedures, $18(12 \%)$ in retroperitoneoscopy and $126(84 \%)$ in laparoscopy.

55 procedures $(37 \%)$ were performed with “one-trocar" technique. Among the remaining 95 (67\%), in 62 ( $41 \%)$ we used a " $3 \mathrm{~mm}$ " instruments, in $18(12 \%)$ "5 mm" instruments and in $15(14 \%)$ they were mixed $(3 / 5 \mathrm{~mm})$. The duration of the procedure was an average of 59 minutes (range: 20-135 minutes) in diagnostic procedures and 184 minutes (range: 40-370 minutes) in the therapeutic procedures. The mean length of stay in the diagnostic procedures was 3 days

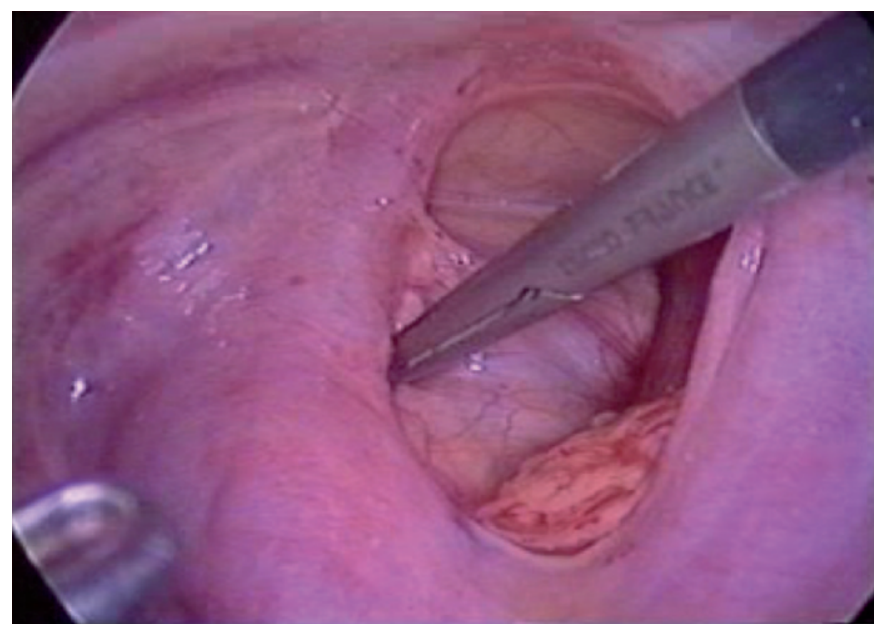

Figure 1. Congenital diaphragmatic intraoperative hernia picture. (range 2-4 days) and therapeutic procedures 4.5 days (range 2-7 days). Were performed conversions equal to $14 / 150(9 \%)$. No intraoperative complication, no accident and no postoperative complication.

The survival rate was $100 \%$.

Analgesic requirements was 24 hours (paracetamol + codeine) in diagnostic and 48 hours (tramadol + ketorolac continuous infusion) in the therapeutic procedures. Feeding started on average after 9.5 hours (range: 6-24 hours) diagnostic and 24 hours (range 1236 hours) in the therapeutic procedures.

We analyzed statistically the following parameters (Table 4) with Fish test:

- Conversion rate: $\mathrm{P}$ value equal to 0.0096 ;

Table 1. Laparoscopic procedures in children under 3 years.

\begin{tabular}{lc}
\hline Procedures & N. \\
\hline Inguinal hernia & 20 \\
\hline Non-palpable testis & 75 \\
\hline Hirschsprung disease (surgery) & 9 \\
\hline Hirschsprung disease (biopsy) & 6 \\
\hline Ovarian tumors & 4 \\
\hline DSD & 1 \\
\hline Funduplicatio & 10 \\
\hline Total & $126(84 \%)$ \\
\hline
\end{tabular}

Table 2. Toracoscopy procedures in children under 3 years.

\begin{tabular}{lc}
\hline Procedures & N. \\
\hline Esophageal atresia & 3 \\
\hline Congenital diaphragmatic hernia & 1 \\
\hline CCAM & 1 \\
\hline Thymoma & 1 \\
\hline Total & $6(4 \%)$ \\
\hline
\end{tabular}

Table 3. Retroperitoneoscopic procedures in children under 3 years.

\begin{tabular}{lc}
\hline Procedures & N. \\
\hline Stenosis of uretero-pelvic junction & 8 \\
\hline Nephrectomy & 6 \\
\hline Eminephrectomy & 4 \\
\hline Total & $18(12 \%)$ \\
\hline
\end{tabular}


- Early complications: P value equal to 1.0000 ;

- Late complications: P value equal to 0.3687 .

Feeding, analgesic requirements and the average time to process are basically the same so we did not run any statistical test.

\section{DISCUSSION}

Analyzing what are the results of our study it is clear that the MIS approach can be considered routine for a wide range of diseases that affect not only adolescents and pre-pubertal but also infants and children within the three years.

What looked like a problem until a few years ago, such as minimally invasive procedures in children, particularly in children under 36 months, today it has become an approach feasible without additional risks of particular relevance to the traditional approach in like age or minimally invasive procedures in older patients.

The evidence for this view comes from the observation of our series, where the total of 900 procedures performed in the last 11 years, $16 \%$ (150 procedures) were performed in patients by the third year of age.

This was made possible in particular by the miniaturization of the instruments. They are in fact now in use 3 $\mathrm{mm}$ trocar, with lengths reduced compared to the adult, which allow a movement within the operating cavity and ergonomics for the operator that guarantees a complete reliability to the MIS procedures in the small patient.

Laparoscopy is certainly the MIS approach that of choice in different type of disease. However even thoracoscopy and retroperitoneoscopy, as demonstrated by our series, can be applied without much difficulty.

The diagnosis is most important in the population of less than 3 years of life and many authors emphasize the merits of laparoscopic surgery especially for the accuracy of the diagnosis, the vision of the anatomical structures, for reduced hospitalization with a rapid return to the routine activity as reported in the work of Higashimoto,

Table 4. Statistical analysis: conversion to open, early and late complications.

\begin{tabular}{lcc}
\hline Analysis & N./ Tot & P-value \\
\hline $\begin{array}{l}\text { Conversion in “open" } \\
<3 \text { years }\end{array}$ & $14 / 150$ & 0.0096 \\
$>3$ years & $30 / 783$ & \\
\hline $\begin{array}{l}\text { Early complications } \\
\quad 3 \text { years }\end{array}$ & $0 / 150$ & 1.0000 \\
$>3$ years & $5 / 783$ & \\
\hline Late complications & & \\
$\quad<3$ years & $0 / 150$ & 0.3687 \\
$>3$ years & $7 / 783$ & \\
\hline
\end{tabular}

Cohen, Waldschmidt, Van der Zee et al [7-11].

Also the analysis of the type of procedures performed shows that now almost all of the laparoscopic surgery, thoracoscopic and retroperitoneoscopic that are performed in patients with more than three years of age is perfectly reproducible in individuals under three years, although the difference pathologies encountered in the two age groups [12-16].

Statistical analysis of our population ( $<3$ years) compared to more than 3 years has given different results based on the aspects considered.

The mean duration of the intervention, the average hospital stay, analgesic requirements and early postoperative nutrition are equivalent results.

The conversion rate in "open" surgery for laparoscopic procedures was higher in young patients $(9 \%$ versus $4 \%$ ) with a statistically significant $P$ value.

The reasons for this difference are to be found in the characteristics of the patients themselves: the volume of the cavity surgery in patients under three years of age decreases exponentially compared to that of older patients; in these conditions the possibility of a movement, of a difficult or incomplete view of the problem to be treated are more frequent for the surgeon and more easily require conversion to "open" technique [17-19].

This is why, however, on the basis of all these considerations the conversion in patients younger should not be considered a "failure" of the MIS but simply a potential problem that does not undermine the effectiveness of minimally invasive in children less than three years of life.

The other parameter that we compared statistically is the rate of early and late complications.

Our results have shown a "P value" not statistically significant, underlying how the MIS does not increase the risk of complications in young patients, and this allows us to conclude that the MIS in children currently is an optimal solution for the patient with age under 3 years.

\section{CONCLUSIONS}

The miniaturization of instruments, the development of sophisticated new techniques and a greater consensus on the MIS has allowed the widespread use of this procedure in the pediatric age with further specific applications in newborns and infants.

It is necessary in this type of surgery an adequate learning curve, especially in pediatric patients, even more in newborns and infants.

The optimum benefits are to be found in the lesser surgical stress, the lower cavity contamination, the magnification of details, the reduced hospital stay, reduced morbidity or the best aesthetic result. All these aspects have helped to improve the surgical and anesthetic techniques also stubbornly and always trying to get a lower rate of complications. 


\section{REFERENCES}

1. Gans $S L$, Berci G. Peritoneoscopy in infants and children. J Pediatr Surg 1973;8:399-405.

2. Hirsig J, Rickham PP. Early differential diagnosis between neonatal hepatitis and biliary atresia. J Ped Surg 1980;15:13-5.

3. Hirsig J, Baals H, Stauffer UG et al. Dumping syndrome following Nissen's fundoplication: a cause for refusal to feed. J Ped Surg 1984;19:155-7.

4. Bax NMA, Georgeson KE, Rothemberg SS et al. Endoscopic surgery in infants and children. Berlin, Heidelberg: Springer-Velag; 2008.

5. Messina M., Garzi A., Amato G. et al. La cirurgia mini-invasiva in età pediatrica. Giornale degli Ospedali, anno III, 2007; $n^{\circ} 2-3:$ 61-8.

6. Al Qahtani AR, Almaramhi H. Minimal access surgery in neonates and infants. J Ped Surg. 2006;41:910-3.

7. Higashimoto $Y$, Nishijima E, Muraji T, et al. Laparoscopy-assisted surgery for neonates with intra-abdominal cysts. Jpn J Pediatr Surg 1994;26:986-92.

8. Cohen Z, Shinhar D, Kopernik G. et al. The laparoscopic approach to uterine adnexal torsion in childhood. J Pediatr Surg 1996;31:1557-9.

9. Waldschmidt J, Schier F. Laparoscopic surgery in neonates and infants. Eur J Pediatr Surg 1991;1:145-50.

10. Garzi A, Amato G, Molinaro F. et al. Cisti ovariche: casistica clinica e revisione della letteratura. Dial Pediatr Surg 2007;3:5-8.
11. Seong YW, Kang CH, Kim JT, et al. Video-assisted thoracoscopic lobectomy in children: safety, efficacy, and risk factors for conversion to thoracotomy. Ann Thorac Surg 2013;95:1236-42.

12. Dingemann C., Ure BM. Minimally invasive repair of esophageal atresia: an update. Eur J Pediatr Surg 2013;23:1061-4.

13. Liem NT. Thoracoscopic approach in management of congenital diaphragmatic hernia. Pediat Surg Int 2013;29:1061-4.

14. Molinaro F, Garzi A, Cerchia E, et al. Thoracoscopic thymectomy in children: our preliminary experience. J Laparoendosc Adv Surg Tech A 2013;23:556-9.

15. Rothemberg SS. Two decades of experience with laparoscopic Nissen fundoplication in infants and children: a critical evaluation of indications, technique, and results. J Laparoendoscopic Adv Surg Tech A 2013;23:791-4.

16. Choi W, Hall NJ, Garriboli M, et al. Outcome following laparoscopic inguinal hernia repair in infants compared with older children. Pediatric Surg Int 2012;28:1165-9.

17. Cerchia E, Molinaro F, Pavone M, et al. Esophageal atresia with distal tracheoesophageal fistula: surgery treatment and a long term follow-up. JASA 2012;4:30-4.

18. Bhatnagar S., Sarin YK. Scope and limitations of minimal invasive surgery in practice of pediatric surgical oncology. Indian J Med Paediatric Oncol 2010;31:137-42.

19. van der Zee DC, van Seumeren IGC, Bax KMA, et al. Laparoscopic approach to surgical management of ovarian cyst in the newborn. J Pediatr Surg 1995;30:42-3. 